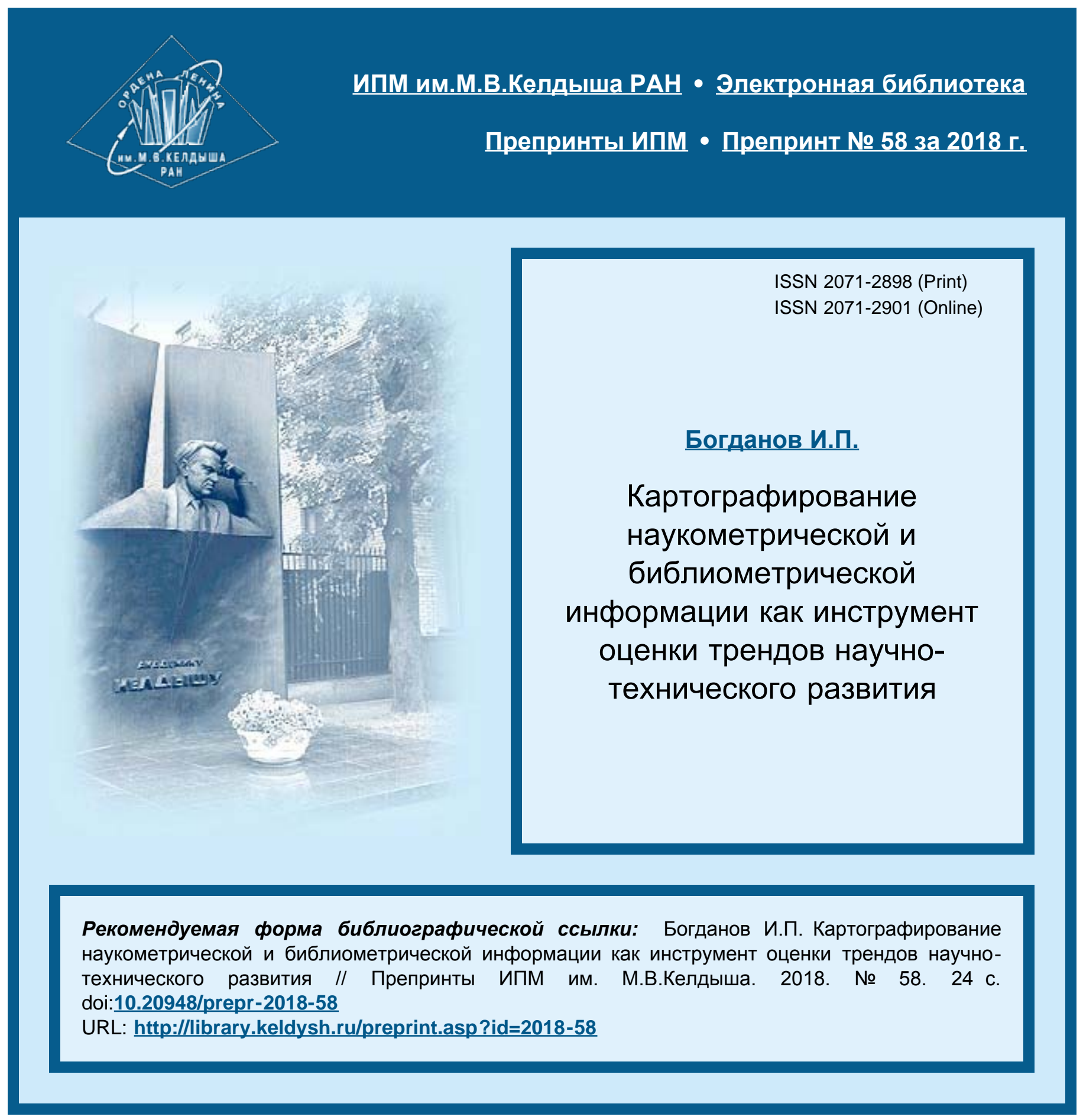




\author{
О рд н н а Л н и на \\ ИНСТИТУТ ПРИКЛАДНОЙ МАТЕМАТИКИ \\ имени М.В.Келдыша \\ Р ос сийской а кадемии на ук
}

И.П.Богданов

Картографирование наукометрической и библиометрической информации как инструмент оценки трендов научно-технического развития 
Богданов И.П.

Картографирование наукометрической и библиометрической информации как инструмент оценки трендов научно-технического развития

В работе рассмотрен метод исследования тенденций научно-технического прогресса, основанный на использовании специальных форм визуального представления наукометрических и библиометрических данных - карт науки и патентных ландшафтов. Приведено описание областей применения, а также основных этапов построения и анализа указанных визуализаций. Рассмотрены факторы, которые необходимо принимать во внимание при изучении карт науки и патентных ландшафтов, а также условия, при выполнении которых результаты данных исследований могут быть эффективно применены при определении перспективных направлений научно-технологического развития.

Ключевые слова: междисциплинарные исследования, карты науки, патентные ландшафты, прогноз научно-технического развития

\section{Ilya Petrovich Bogdanov \\ Scientific trends assessment via mapping of scientometric and bibliometric data}

The paper focuses on the method of scientific trends forecasting, based on the implementation of special visual representations of scientometric and bibliometric data - maps of science and patent landscapes. Main applications, general mapping process steps and principles of analysis for the regarded visualizations are described. The paper also presents factors that should be considered when defining promising research areas via investigation of maps of science and patent landscapes.

Key words: interdisciplinary research, maps of science, patent landscapes, scientific and technological forecast 


\section{Введение}

Одним из перспективных методов прогнозирования направлений и темпов научно-технологического развития (наряду с такими подходами, как исследование потребностей военно-промышленного комплекса и коммерческого сектора экономики), является построение и анализ специальных форм визуализации библиометрической и наукометрической информации карт науки $[1,2]$ и патентных карт и ландшафтов [3].

\section{Карты науки и технологии: определение и области применения}

К настоящему времени человечеством накоплен огромный объем научнотехнической информации, содержащейся в статьях, монографиях, диссертациях, патентах и т.д. Каждый из указанных источников характеризуется разнообразными библиометрическими признаками - видом и наименованием документа, авторством, предметной областью, названием издания, организацией, в которой было выполнено исследование, ключевыми словами (дескрипторами), библиографическими ссылками и т.д. Данные признаки находятся друг с другом в различных видах взаимоотношений - книга и статья могут принадлежать одному и тому же автору, несколько диссертаций могут быть посвящены моделированию одного и того же физического процесса, несколько исследований могут быть поддержаны одним и тем же грантом и т.д. Таким образом, весь массив научно-технической информации можно представить как изменяющуюся во времени сеть, состоящую из элементов разной природы, соединенных между собой множеством взаимосвязей разной интенсивности. Анализ структуры, закономерностей развития, а также качественных и количественных характеристик такой научной сети является предметом изучения наук библиометрии и наукометрии.

На первом этапе развития библиометрии и наукометрии (60-е-70-е гг. 20 века) основной задачей исследователей была оценка различных научных аспектов на основе количественных показателей (собирался статистический материал по авторам, институтам, странам и т.д.). На втором этапе (80-е гг. 20 в.-начало 21 в.) в связи с развитием алгоритмов и средств визуализации появилось направление, занимающееся построением качественной (структурной) картины науки и отдельных ее областей [4]. Был разработан специальный вид информационного материала - карты науки и технологии, представляющие собой визуальные образы взаимосвязей между различными аспектами научно-технической деятельности (тематиками, корпусами публикаций, журналами, отдельными документами и др.), специальным способом отображенных на плоскость $[1,5]$. Первый прообраз карт науки и технологии был построен еще в 1930-х годах и представлял собой таблицу, столбцы которой соответствовали физическому, биологическому и 
общественному секторам науки, а строки - техническому и фундаментальному подходам [5]. С появлением больших информационных баз, содержащих электронные версии публикаций (Scopus, Web of Science и др.), а также с развитием программно-математических методов обработки больших объемов данных у исследователей появилась возможность формировать компактные, наглядные и информативные изображения (сетевые графы, ландшафты, концептуальные, кластерные, тепловые карты и т.д. [6]) на основе сотен тысяч и миллионов документов.

На рис. 1 приведена карта взаимосвязей научных областей (показанных различными цветами), составленная ведущими учеными в области картографирования науки (Смолл, Бояк и др.) на основе анализа цитирований и ключевых слов в тексте 22 миллионов публикаций и патентов [7]:
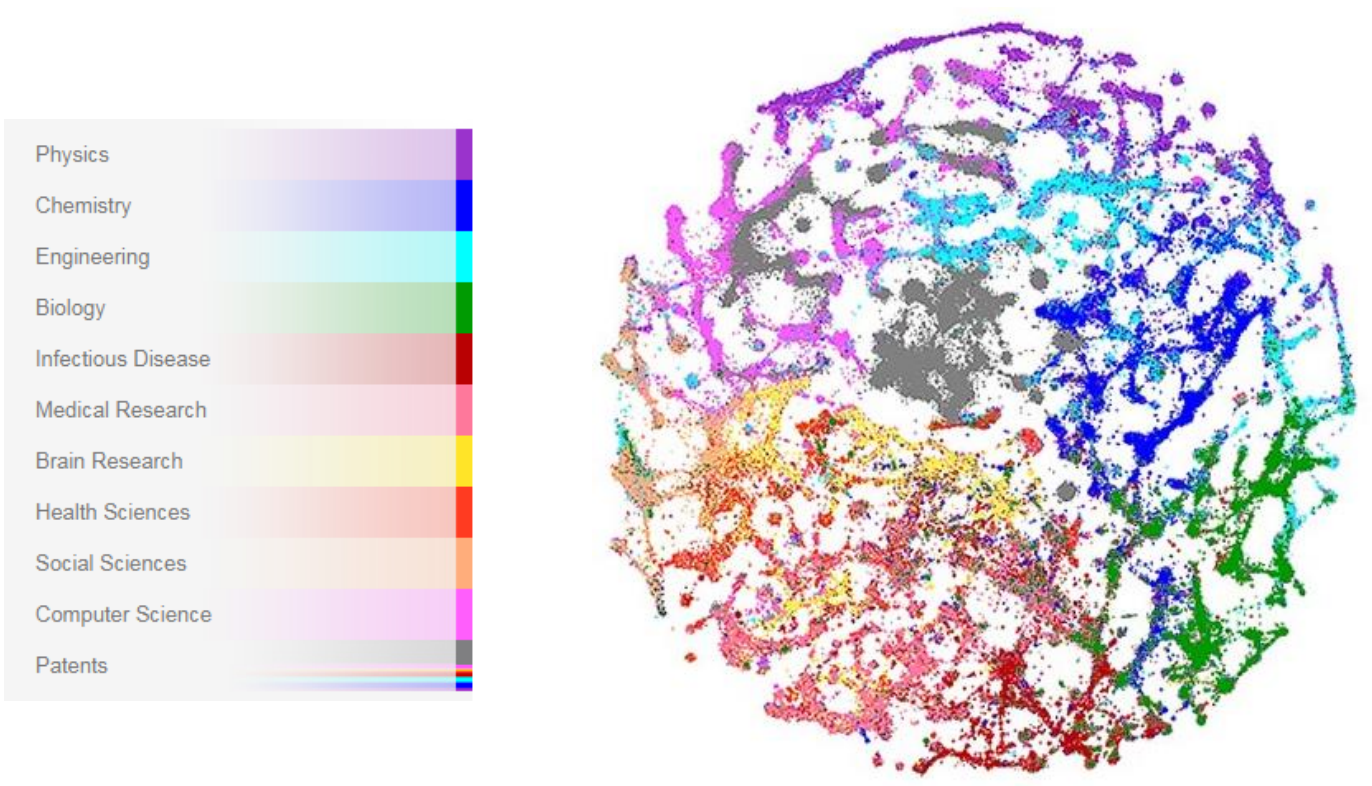

Puc. 1. Карта взаимосвязей областей науки 
На рис. 2 приведен патентный ландшафт технологий 3D-печати, отображающий около 30000 патентных документов [8]. Данные документы сгруппированы в зависимости от совпадения ключевых слов, встречающихся в их названиях и аннотациях. Чем больше документов имеют схожую тематику (т.е. содержат одинаковые дескрипторы), тем «выше» соответствующий им участок ландшафта. На рис. 3 на том же патентном ландшафте отмечены технологические области, к которым относятся указанные патенты [8].

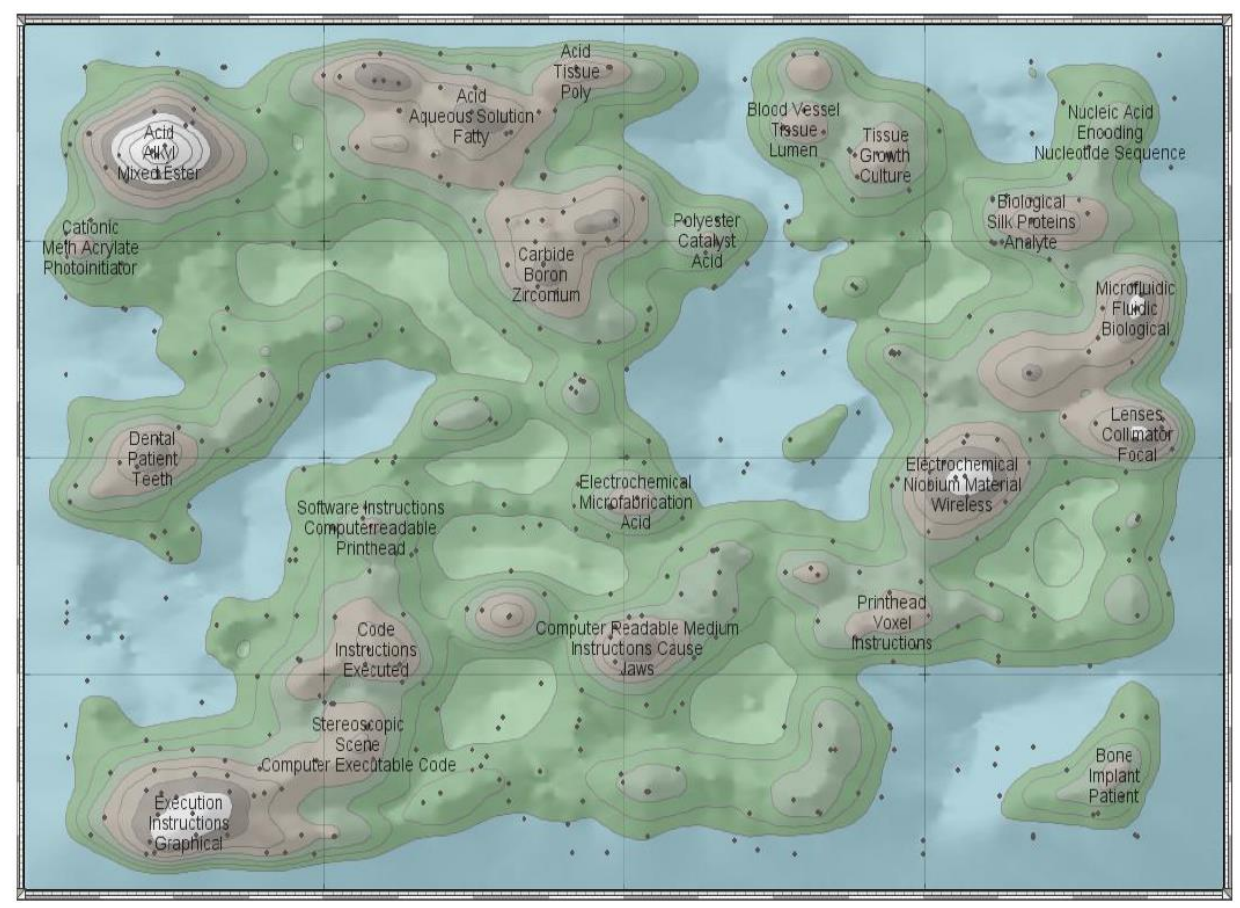

Puc. 2. Патентный ландшафт технологий 3D-печати 


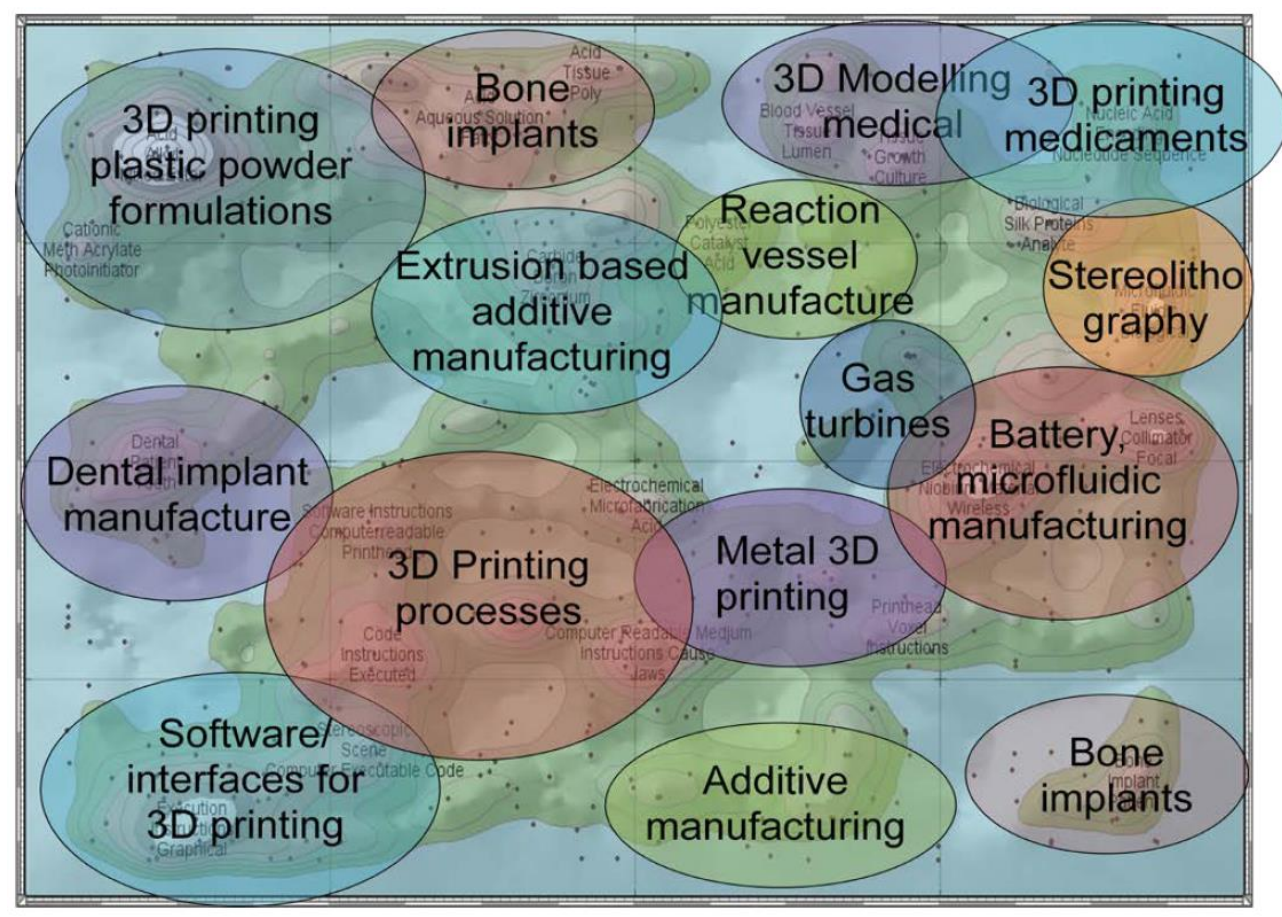

Puc. 3. Патентный ландшафт технологий 3D-печати с отмеченными технологическими областями

Анализируя наборы карт, сформированных на основе больших и представительных массивов информации, можно делать достаточно достоверные выводы относительно текущего состояния исследований в какойлибо предметной области, оценивать динамику прогресса в разработке заданных технологий, выявлять закономерности (в том числе неявные) развития научного знания и научно-технические «прорывы», изучать сети научных коммуникаций, исследовать схемы научного сотрудничества, оценивать производительность исследований, прогнозировать развитие предметной области, осуществлять конкурентную разведку и т.д. В отдельных случаях подробное изучение стыков дисциплин и сопоставление карт/ландшафтов за различные временные периоды позволяет сделать предположения относительно вероятных будущих направлений и темпов исследований, а также обнаруживать зарождающиеся новые области наук $[1,2,5]$. Данные проведенного анализа, сформулированные выводы и предположения могут быть учтены при выборе приоритетов научного и технологического развития, а также определении перспективных направлений развития отраслей промышленности [9].

В настоящее время существует большое количество зарубежных коммерческих и некоммерческих программных комплексов и инструментов, функционал которых позволяет проводить картографирование науки и технологии либо готовить материал, на основе которого карту можно будет построить с помощью средств визуализации $[1,6,10-12]$. Примерами являются IN-SPIRE Visual Document Analysis [13], VantagePoint [14], Derwent Innovation 
[15], INTELLIXIR [16], CiteSpace [17], Science of Science Tool [18], SciMAT [19], Loet Leydesdorff's Software [20], VOSviewer [21], Interdisciplinary Research [22], Network Workbench Tool [23], CopalRed [24], Bibexcel [25] и т.д.

\section{Общая схема построения и анализа}

\section{карт науки и технологии}

Процесс исследования существующих и прогнозирования будущих направлений и темпов научно-технического развития на основе построения и анализа карт начинается с четкой формулировки поставленных целей [9] и постановки задачи (определение технологических трендов, прогнозирование научных «прорывов» и т.д.). В зависимости от поставленной задачи выбираются базовые элементы для анализа (патентные документы, публикации в научных журналах за выбранные годы, наборы параметров, характеризующих деятельность научно-исследовательских групп, и т.д.), на основе которых строится карта.

Общий процесс картографирования и анализа состоит из следующих этапов $[1,11,12]$ :

1. получение разнородных данных из различных информационных источников;

2. предварительная обработка данных;

3. формирование сетей (матриц, таблиц) взаимосвязей между данными;

4. нормализация сетей (матриц, таблиц);

5. построение карт науки и технологии;

6. визуализация карт науки и технологии;

7. анализ карт науки и технологии, получение предварительных выводов и предположений;

8. экспертная оценка полученных выводов и предположений.

\section{Получение разнородных данных из различных информационных источников}

Первым шагом построения карты является извлечение данных из больших массивов научно-технической информации, содержащих полные тексты и/или аннотации документов, сведения об авторах, организации, дате издания, данные о цитированиях, ключевые слова, коды (признаки) систем классификаций или кодифицирования и т.д. На практике в качестве инструментов сбора научной информации наиболее часто используются $[1,5,10-12]$ две крупнейшие по объемам индексируемых материалов международные мультидисциплинарные информационно-поисковые системы Scopus [26] и Web of Science [27] (доступные через веб-интерфейс при условии оформления подписки), а также бесплатная поисковая система Google Scholar [28]. 
Информационно-поисковая система Scopus (разработанная и поддерживаемая компанией Elsevier) содержит регулярно обновляемую информацию о публикациях в научных изданиях, книгах, отраслевых журналах, материалах конференций, патентах и т.д. Scopus предоставляет возможность расширенного поиска ${ }^{1}$ (по аннотациям, ключевым словам, предметным областям, авторам, выходным данным изданий и т.д.) сведений о документах, журналах и авторах: текстов аннотаций ${ }^{2}$, списков цитирований и использованных источников, соавторов и т.д. Информационно-поисковая система Web of Science (разработанная Институтом научной информации (ISI) и в настоящее время принадлежащая компании Clarivate Analytics) функционирует аналогично Scopus, обеспечивая возможность расширенного поиска (по авторам, типам документов, периодам публикации, номерам грантов и т.д.) постоянно обновляемых данных о журнальных статьях, монографиях, патентах, а также материалах конференций, симпозиумов и круглых столов. Основное различие между рассматриваемыми базами данных заключается в несовпадении наборов индексируемых ими изданий.

Google Scholar представляет собой Интернет-сервис, позволяющий осуществлять поиск по полным текстам либо описаниям научных и технических документов (статей в научных журналах, книг, материалов конференций, препринтов, диссертаций, технических отчетов, патентов и т.д.), как находящихся в свободном доступе, так и требующих платных подписок [29]. Результатами поиска являются ссылки на страницы публикаций (на сайтах соответствующих изданий) и списки цитирований. По порядку общего числа индексируемых документов бесплатный сервис Google Scholar сопоставим с коммерческими базами данных Scopus и Web of Science, но при этом не обеспечивает полного охвата рецензируемых ими материалов и не может считаться их заменой [29-30]. Кроме того, при использовании Google Scholar в результаты поиска теоретически могут попасть статьи из журналов, не отличающихся высоким научным уровнем (в отличие от Scopus и Web of Science, уделяющих существенное внимание качеству публикаций при отборе индексируемых изданий).

Кроме крупных междисциплинарных поисковых систем, существуют специализированные поисковые системы, индексирующие публикации, относящиеся к какой-либо конкретной предметной области. Например, IEEE Xplore Digital Library [31] осуществляет поиск по базе данных публикаций Института инженеров электротехники и электроники (IEEE) и Института инженерии и технологий (IET), PubMed [32], созданная Национальным центром биотехнологической информации США (NCBI), - по базе данных медицинских

\footnotetext{
1 B Scopus также предусмотрена возможность бесплатного поиска списков публикаций, соавторов и цитирований по автору.

2 Доступ к полным текстам для ряда публикаций и книг может быть получен с помощью коммерческой системы ScienceDirect (URL: http://www.sciencedirect.com, дата обращения: 11.04.2018), также разработанной компанией Elsevier.
} 
и биологических публикаций, MathSciNet [33], разработанная Американским Математическим Обществом (AMS), - по базе данных математических публикаций. Также существуют национальные научные электронные библиотеки (например, российская eLIBRARY.RU [34]) и национальные библиотеки диссертаций (например, Электронная библиотека диссертаций Российской государственной библиотеки [35]).

Основными инструментами сбора данных по патентной документации являются [6]:

1. бесплатные информационно-поисковые системы международных патентных организаций: PATENTSCOPE [36] Всемирной организации интеллектуальной собственности (WIPO), Espacenet [37] Европейского патентного ведомства (ЕРО);

2. бесплатные информационно-поисковые системы национальных патентных ведомств, в том числе российского Федерального института промышленной собственности (ФИПС) [38] и Ведомства по патентам и торговым знакам (USPTO) США [39];

3. коммерческие системы: LexisNexis TotalPatent [40], Derwent Innovation [15], Global Patent Index [41], PATSTAT [42], Questel Orbit [43], Minesoft PatBase [44], WIPS Global [45], Gridlogics PatSeer [46] и др.

\section{Предварительная обработка данных}

На этапе предварительной обработки происходят преобразование и группировка данных, полученных из источника, с целью повышения качества формируемой карты. Например, в исходных данных могут содержаться опечатки (в фамилии автора, ключевых словах и т.д.), часть сведений может быть продублирована, а часть - пропущена. Методы предварительной обработки позволяют скорректировать некоторые из указанных неточностей исправить ошибки, удалить повторяющиеся данные, добавить недостающую информацию [1, 12].

Другой пример: если формируемую карту предполагается использовать для анализа динамики исследований в заданной предметной области либо эволюции некоторых научных областей, то исходные данные целесообразно предварительно разделить на классы в зависимости от временного периода, к которому они относятся $[1,11,12]$.

Также, если формируемая карта будет строиться на анализе совместно встречающихся ключевых слов, может осуществляться удаление заведомо несущественных данных и объединение элементов, представляющих одно и то же понятие [1, 12]. 


\section{Формирование сетей (матриц, таблиц) взаимосвязей между данными}

После завершения предварительной обработки исходных данных необходимо определить, по какому принципу между ними будут строиться взаимосвязи, и сформировать сеть (матрицу, таблицу) в соответствии с выбранным принципом. Указанные связи могут строиться на основе анализа цитирования, совместно встречающихся ключевых слов, соавторства, совместного использования грантов и т.д. $[1,5,11,12]$. Кроме того, возможно применение комбинированных подходов $[5,7,12]$.

Взаимосвязи, основанные на соавторстве, образуются между авторами, опубликовавшими совместную статью, а также между институтами/странами, сотрудники/граждане которых опубликовали совместную статью $[1,11]$.

Взаимосвязи, основанные на цитировании, могут строиться несколькими способами:

1. документ А и документ Б образуют соотношение «прямая связь между документами», если в А содержится ссылка на Б [5];

2. документы А и Б образуют отношение «документное библиографическое сочетание» [47], если в них содержатся ссылки на одни и те же документы (см. рис. 4);

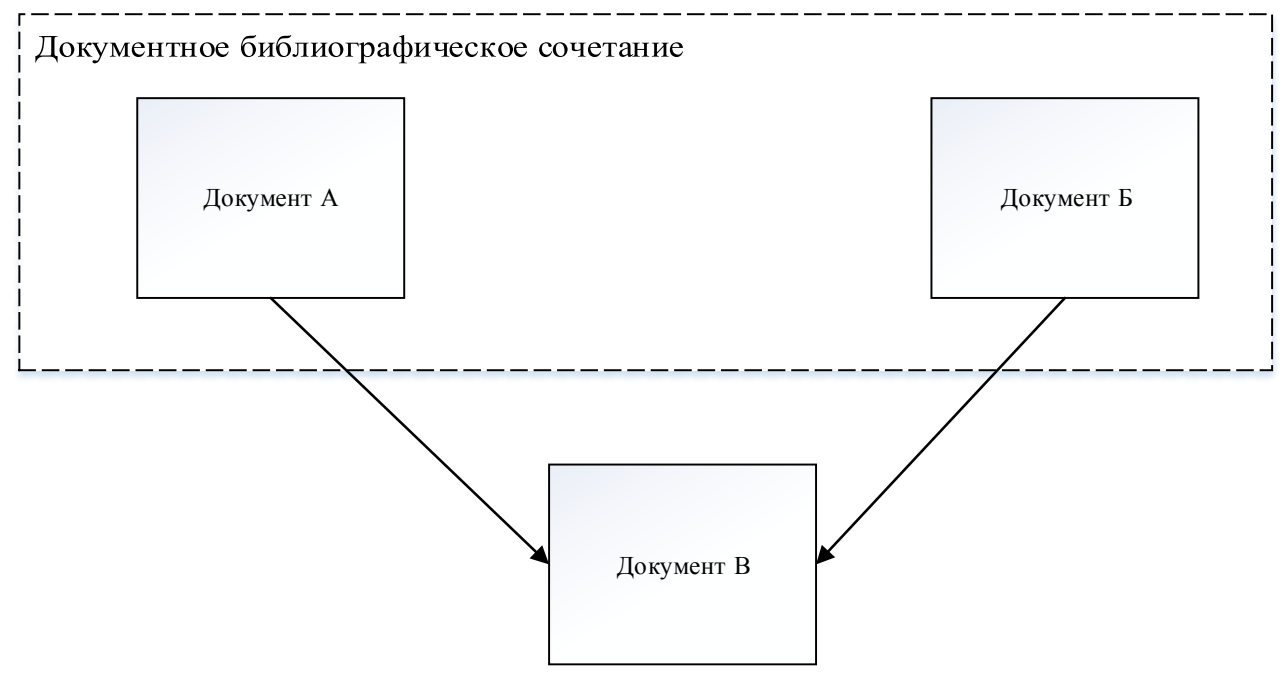

Рис. 4. Документное библиографическое сочетание 
3. корпусы публикаций (статьи в научных журналах, материалы конференций, монографии и т.д.) авторов А и Б образуют отношение «авторское библиографическое сочетание» [48], если в документах данных корпусов содержатся ссылки на одни и те же документы (см. рис. 5);

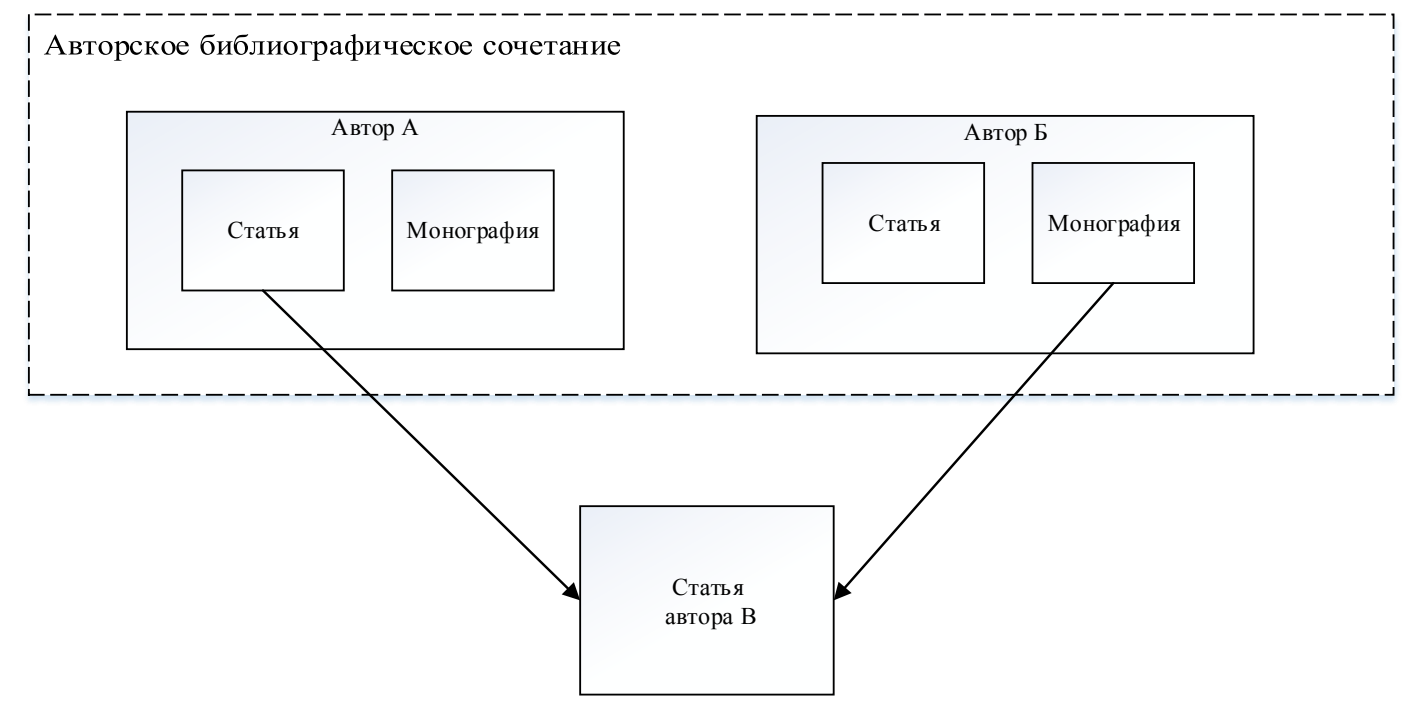

Рис. 5. Авторское библиографическое сочетание

4. документы А и Б образуют отношение «документное коцитирование» [49], если на них одновременно ссылается какой-либо документ (см. рис. 6);

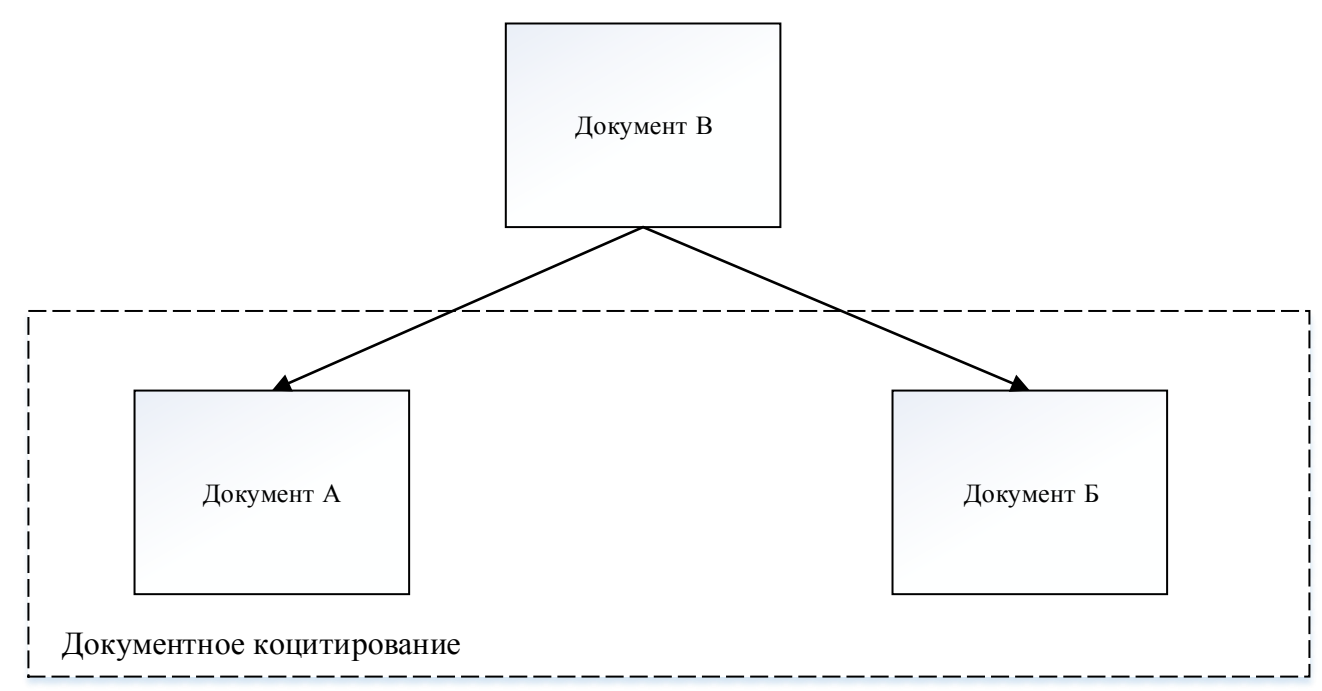

Рис. 6. Документное коцитирование

5. корпусы публикаций авторов А и Б образуют отношение «авторское коцитирование» [50], если существуют документы, одновременно ссылающиеся на одну из публикаций (любую) автора А и одну из публикаций (любую) автора Б (см. рис. 7); 


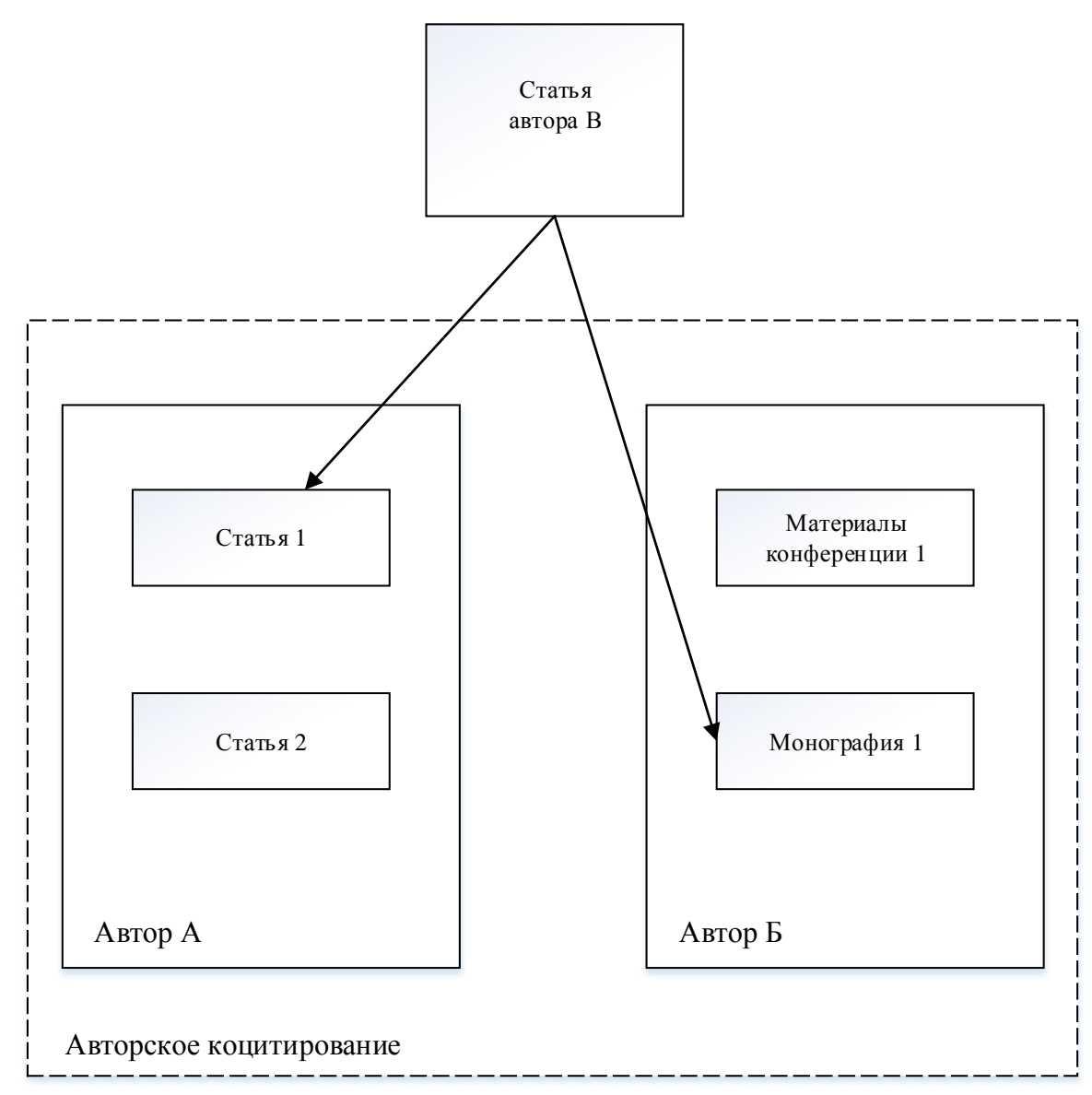

Рис. 7. Авторское коцитирование

6. отношения «журнальное библиографическое сочетание» и «журнальное коцитирование» строятся аналогично отношениям «авторское библиографическое сочетание» и «авторское коцитирование» (вместо корпуса публикаций конкретного автора рассматривается корпус публикаций конкретного журнала) [1].

При анализе совместно встречающихся ключевых слов $[1,5,51,52]$ каждому документу коллекции ставится в соответствие набор дескрипторов, описывающих его содержание. Взаимосвязь между дескрипторами образуется, если они совместно встречаются в описании хотя бы одного документа.

\section{Нормализация сетей (матриц, таблиц)}

После формирования сети (матрицы, таблицы) необходимо количественно оценить степени сходства составляющих их элементов (т.е. провести нормализацию [1]). Такая численная оценка осуществляется с помощью мер подобия - косинусной меры Солтона, индекса Жаккара, индекса включения, индекса эквивалентности и т.д. $[1,5,11]$. 
Косинусная мера подобия Солтона основана на идее использования косинуса угла между векторами для оценки отклонения данных векторов: $\langle\mathbf{a}, \mathbf{b}\rangle /(\|\mathbf{a}\| \cdot\|\mathbf{b}\|)$, где $\mathbf{a}, \mathbf{b}$ - векторы, $\langle\cdot, \cdot\rangle$ - скалярное произведение, $\|\cdot\|$ - мера. Чем ближе к единице косинус (а угол, соответственно, к нулю), тем меньше отклонение векторов. Чем ближе данный косинус к нулю (а угол - к $\pi / 2$ ), тем менее общего между тематикой документов [5]. Например, для случая, когда связи в сети строятся по принципу «документное библиографическое сочетание», косинусная мера подобия для документов $i$ и $j$ задается формулой (1):

$$
S_{1}(i, j)=\frac{b s(i, j)}{\sqrt{\operatorname{cim}(i) \cdot \operatorname{cim}(j)}},
$$

где $b s(i, j)$ - количество документов, цитируемых и в $i$ и в $j, \operatorname{cim}(i)-$ количество документов, цитируемых в $i, \operatorname{cim}(j)$ - количество документов, цитируемых в $j$.

Индекс Жаккара основан на использовании показателя сходства (различия) двух наборов предметов $A$ и $B:|A \cap B| /|A \cup B|$ (отношение мощности множества предметов, входящих и в набор $A$, и в набор $B$, к мощности множества всех предметов, входящих хотя бы в один из указанных наборов). В случае, когда связи в сети строятся по принципу «документное коцитирование», данная мера подобия для документов $i$ и $j$ задается формулой (2) [5]:

$$
S_{2}(i, j)=\frac{\operatorname{coc}(i, j)}{\operatorname{cit}(i)+\operatorname{cit}(j)-\operatorname{coc}(i, j)}
$$

где $\operatorname{coc}(i, j)$ - количество документов, цитирующих и $i$ и $j, \operatorname{cit}(i)-$ количество документов, цитирующих $i, \operatorname{cit}(j)$ - количество документов, цитирующих $j$.

Индекс включения и индекс эквивалентности для дескрипторов $k$ и $l$ (в случае взаимосвязей, основанных на анализе совместно встречающихся ключевых слов) задаются выражениями (3) и (4) соответственно [51, 52]:

$$
\begin{gathered}
S_{3}(k, l)=\frac{c_{k l}}{\min \left(c_{k}, c_{l}\right)}, \\
S_{4}(k, l)=\frac{c_{k l}^{2}}{c_{k} \cdot c_{l}},
\end{gathered}
$$


где $c_{k l}-$ количество документов, в описании которых встречаются и дескриптор $k$ и дескриптор $l, c_{k}-$ количество документов, в описании которых встречается дескриптор $k, c_{l}$ - количество документов, в описании которых встречается дескриптор $l$.

\section{Построение карт науки и технологии}

Сеть (матрица, таблица), сформированная на этапе № 3 и прошедшая процедуру нормализации на этапе № 4, представляет собой сложную многомерную систему, состоящую из большого числа элементов. Для того чтобы сформировать на ее основе компактную, информативную и наглядную карту, необходимо упростить данную сеть (матрицу, таблицу), понизить ее размерность и отобразить на плоскость таким образом, чтобы пары элементов с высокими показателями сходства располагались бы на указанной плоскости ближе друг к другу, чем пары элементов с меньшими показателями.

Упрощение сети (матрицы, таблицы), как правило, осуществляется методами кластеризации, т.е. разбиения элементов на группы (кластеры) таким образом, чтобы элементы, входящие в один кластер, обладали схожими свойствами, а элементы разных кластеров - существенно различались [5]. При этом кластеры не должны быть ни слишком маленькими (в этом случае карта будет сложна для восприятия), ни слишком большими (в этом случае ряд закономерностей будет незаметен). Такое преобразование упрощает исходную систему и при этом сохраняет свойства ее структуры [53]. Примеры способов кластеризации данных, основанных на анализе коцитирования и совместно встречающихся ключевых слов, приведены в [5].

Для понижения размерности применяются следующие методы: декомпозиция на основе собственных векторов и собственных значений, метод сингулярного разложения, факторный анализ и метод главных компонент, многомерное шкалирование, масштабирование на основе Pathfinder Network Scaling, использование самоорганизующихся карт [5, 53].

Для отображения данных на двумерную плоскость применяются, например, методы триангуляции либо силовых алгоритмов [5, 53].

\section{Визуализация карт науки и технологии}

На рис. 8-11 приведены примеры визуализированных карт науки и технологии, сформированных с помощью трех программных комплексов (обзоры различных техник визуализации можно найти в $[1,54]$ ). 
На рис. 8 показана карта взаимосвязей между тематиками публикаций в ведущих научных изданиях, визуализированная с помощью системы VOSviewer $[2,55]$. Данная карта построена на основе анализа журнального коцитирования (рассматривались цитирования статьями, опубликованными в 2007 г., статей, опубликованных в 5000 ведущих научных журналах за предшествующие 10 лет). Площади кругов пропорциональны числам публикаций в источниках, цвета соответствуют различным тематикам, взаимное расположение отражает количество совместных цитирований.

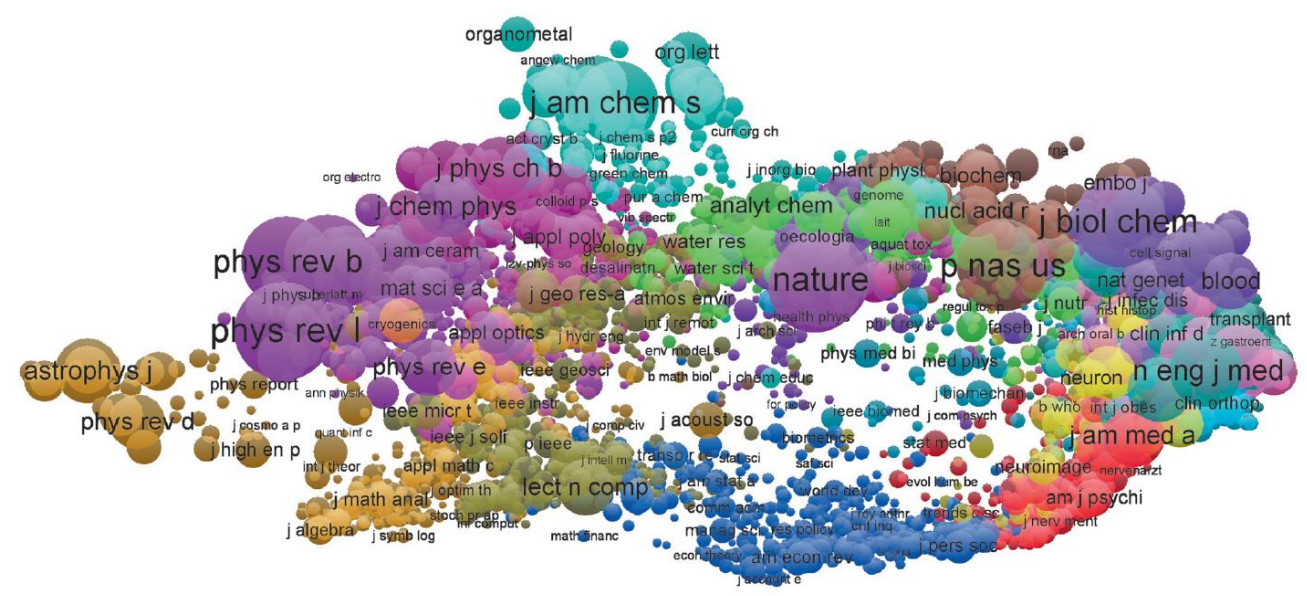

Puc. 8. Карта взаимосвязей тематик публикаций ведущих научных журналов

На рис. 9 приведена карта взаимосвязей естественных и инженерных наук ${ }^{3}$, визуализированная с помощью системы Interdisciplinary Research [56-58]. Данная карта построена на основе анализа цитирований публикаций в изданиях, индексируемых системой Web of Science (2006 г.).

На рис. 10 показана концептуальная структура области исследований нечетких множеств, визуализированная с помощью системы VOSviewer [1]. Для построения данной карты был использован анализ совместно встречающихся ключевых слов в статьях соответствующей тематики, опубликованных в период с 2005 г. по 2009 г. Чем чаще встречается совместное употребление конкретных дескрипторов (т.е. чем сильнее они связаны друг с другом по смыслу), тем ближе их расположение на карте. Чем чаще встречается конкретный дескриптор, тем больше размер соответствующей ему метки.

\footnotetext{
${ }^{3}$ В соответствии с классификацией Института научной информации ISI (URL: https://images.webofknowledge.com/images/help/WOS/hp_subject_category_terms_tasca.html, дата обращения: 11.04.2018).
} 


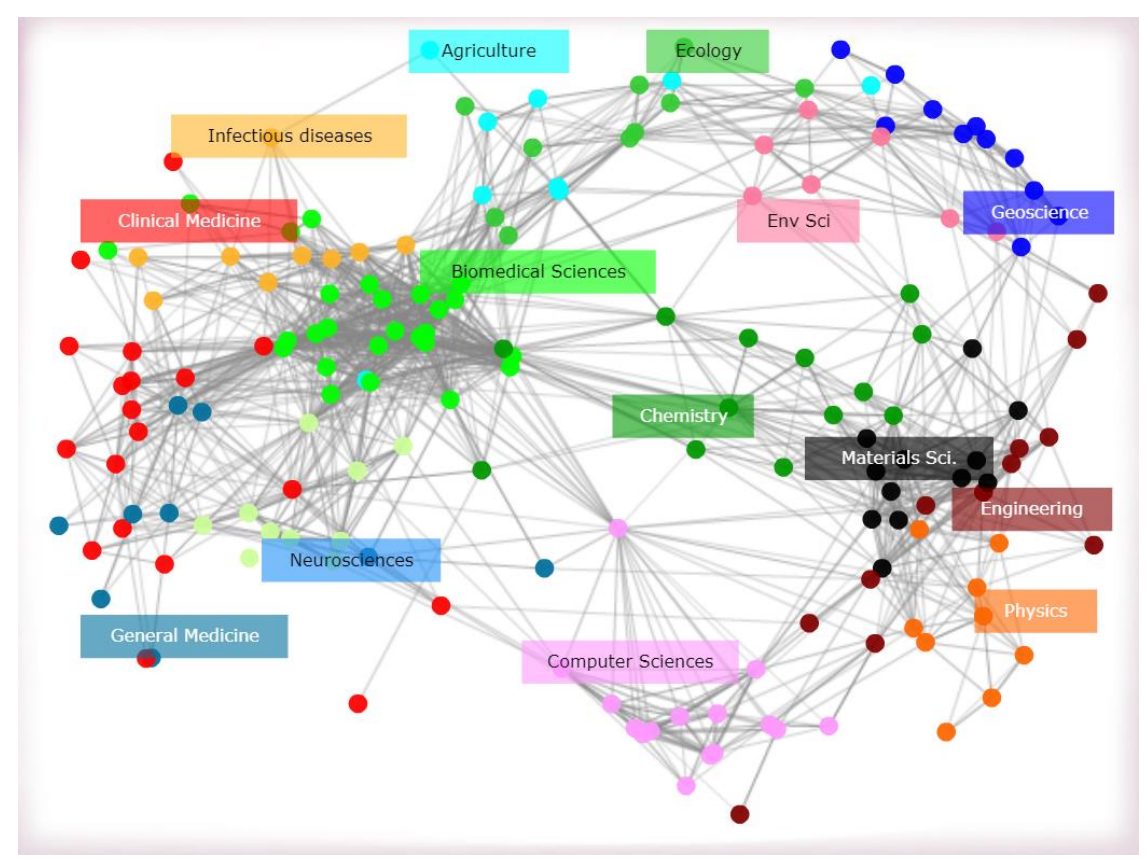

Puc. 9. Карта взаимосвязей естественных и инженерных наук

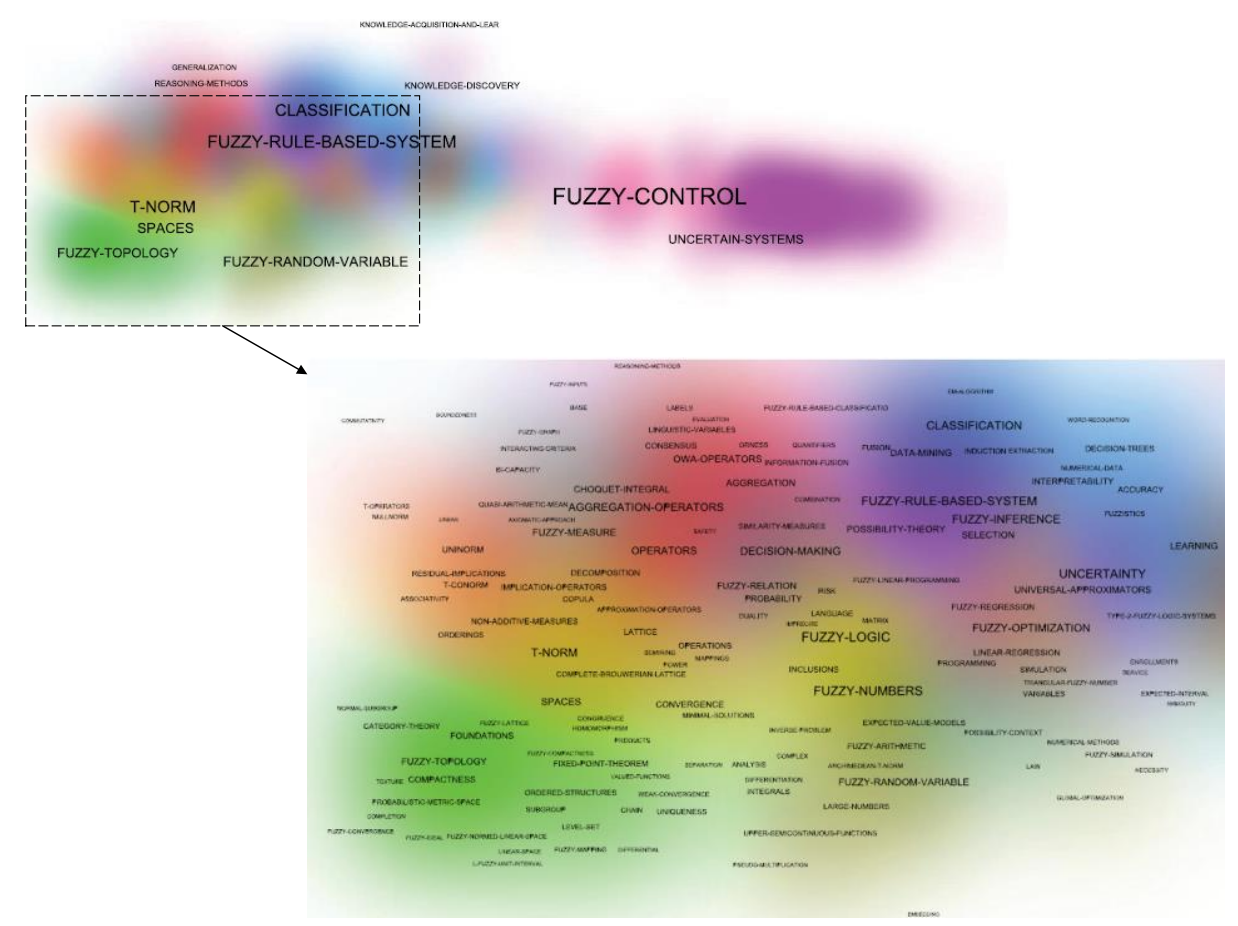

Рuc. 10. Концептуальная структура области исследований нечетких множеств

На рис. 11 и 12 приведены примеры патентных ландшафтов, сформированных с помощью системы Thomson Innovation ${ }^{4}$. Данные ландшафты построены на основе анализа совпадения ключевых слов в описаниях патентных формул.

\footnotetext{
${ }^{4}$ В настоящее время данная система называется Derwent Innovation [15].
} 
На рис. 11 показан патентный ландшафт в области нанотехнологий [59].

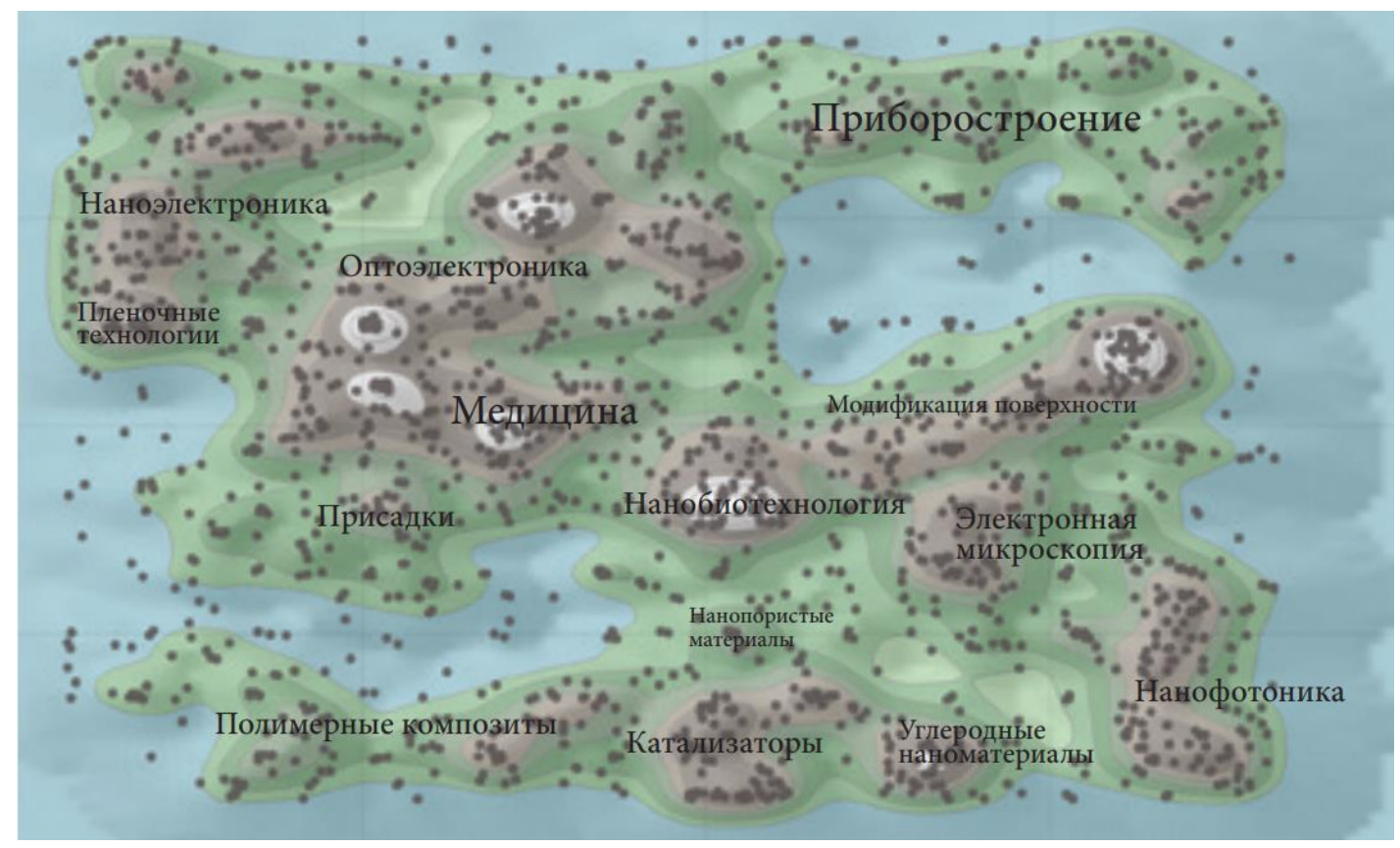

Puc. 11. Патентный ландшафт в области нанотехнологий

Рис. 12 отображает патенты, полученные Уральским федеральным университетом в период с 1993 г. по 2001 г. (различными цветами показаны различные тематические области) [2].

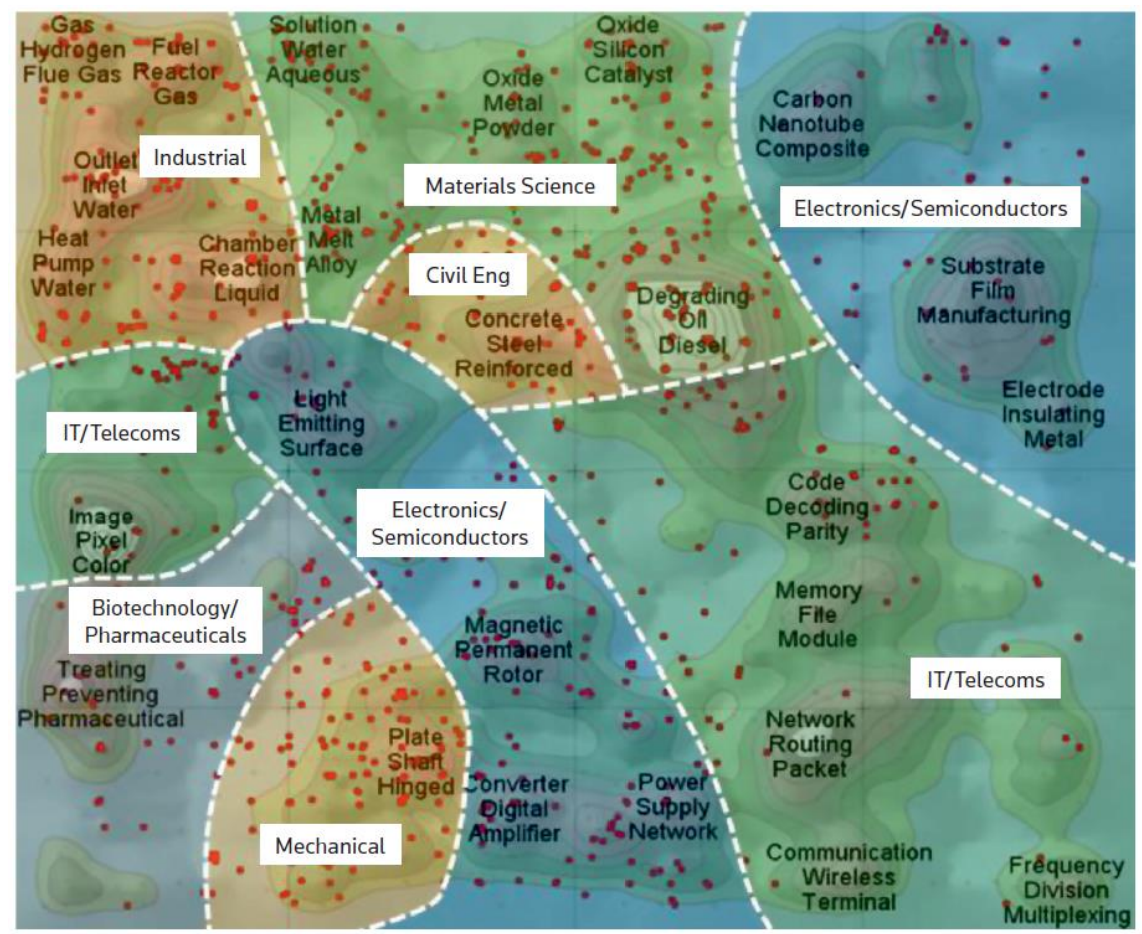

Puc. 12. Патентный ландшафт Уральского федерального университета 


\section{Анализ карт науки и технологии, получение предварительных выводов и предположений}

Сформировав набор визуальных образов, исследователь (опираясь в немалой степени на свой опыт, знания и интуицию [1]) приступает к анализу статистических, тематических, сетевых, временных и геопространственных аспектов [2].

Изучая патентные ландшафты, в том числе аналогичные изображенным на рис. 2, 3, 11, можно делать достаточно уверенные выводы относительно процессов развития и смены технологических укладов, а также жизненных циклов инновационных продуктов [9].

Исследуя карты науки, аналогичные изображенным на рис. 8 и 9, можно выделять наиболее интенсивно развивающиеся тематики и делать предположения относительно вероятности достижения в будущем качественно новых научных результатов на накопленном базисе.

Анализируя активность научно-исследовательских групп (международное сотрудничество, участие в конференциях, обсуждениях, симпозиумах и т.д.), можно делать достаточно обоснованные предположения относительно вероятности достижения в будущем качественно новых научных результатов в конкретной лаборатории или институте.

Рассматривая области резкого роста публикационной активности на картах наук либо патентной активности на патентных ландшафтах, можно с приемлемой достоверностью идентифицировать научно-технологические «прорывы» [60]. С другой стороны, резкий спад количества публикаций конкретной тематики, наблюдаемый в конкретной стране, может сигнализировать о том, что разработки в данном направлении достигли такого уровня, при котором было принято решение, например, засекретить их.

Анализируя динамику увеличения числа запросов к полным текстам статей определенной тематики, можно выявлять направления, по которым уже начались работы, но еще не появилось опубликованных результатов [2].

Акцентируя внимание на стыках традиционных предметных областей на картах наук, можно обнаруживать появление новых перспективных междисциплинарных подходов и методов.

Проводя ретроспективный анализ, рассматривая исторические тренды и идентифицируя паттерны на картах наук и патентных ландшафтах, можно исследовать закономерности (в том числе неявные) процессов развития науки и техники и на их основе строить предположения относительно динамики соответствующих процессов в будущем. 


\section{Экспертная оценка полученных выводов и предположений}

Проводя экспертную оценку качества предварительных выводов и предположений и анализируя их пригодность и полезность для выработки управленческих решений по определению перспективных направлений научнотехнологического развития, требуется принимать во внимание ряд существенных факторов.

Во-первых, эксперту необходимо оценить актуальность, корректность, полноту, релевантность, непротиворечивость и репрезентативность данных, используемых для анализа. Требуется принимать во внимание, что проходит определенное время, прежде чем по результатам исследований и разработок будет опубликована научная статья либо оформлен патент. В названиях, ключевых словах и полных текстах анализируемых документов могут содержаться орфографические ошибки. Ряд публикаций может отсутствовать в открытом доступе. Некоторые технологии могут быть закрытыми, и информация о них не будет содержаться в патентных базах. В список обрабатываемых источников могут попасть журналы, не характеризующиеся высоким научным уровнем (публикации в таких изданиях могут не соответствовать дескрипторам, содержать некорректные цитирования и т.д.). Кроме того, необходимо иметь в виду возможность намеренной дезинформации, осуществляемой конкретной компанией или страной, стремящейся продвинуть свой товар на рынке, обеспечить информационную безопасность своих разработок или подвигнуть конкурентов к трате ресурсов на развитие бесперспективных направлений. Для учета перечисленных факторов эксперту требуется ответить на вопросы, насколько надежными, обширными и представительными являлись привлеченные разнородные источники информации (архивы научных изданий, патентные библиотеки, отчеты о научно-исследовательских и опытно-конструкторских работах, отраслевые журналы, стратегии развития крупных компаний и др.), каким образом принимались во внимание особенности каждого из источников, каковы были условия получения информации, какие методы применялись для обработки больших массивов данных (в частности, как корректировались ошибки и отфильтровывалась несущественная информация), как согласуются между собой различные информационные сообщения и т.д.

Во-вторых, эксперту необходимо оценить соответствие примененных методов поставленным целям и задачам. Например, на основе изучения патентных ландшафтов стран, являющихся технологическими лидерами, можно получить представление о существующих тенденциях научно-технического прогресса [9]. Но если некий субъект при определении своих приоритетов долгосрочного развития будет ориентироваться только на тренды, выявленные на основании анализа патентных ландшафтов стран-лидеров, то данный субъект будет перманентно находиться в роли догоняющего [2]. 
В-третьих, эксперту необходимо оценить, насколько глубоким и системным является проведенный анализ. Выводы должны основываться на комбинации взаимодополняющих исследований наборов карт и ландшафтов, построенных для различных временных периодов, различных видов логических взаимосвязей и т.д. Например, некоторое направление исследований может выделяться на тематических картах наук за счет большого числа статей и цитирований. При этом дополнительное изучение сетей соавторства и геопространственный анализ могут продемонстрировать, что исследования по данной тематике локализуются внутри конкретного коллектива (члены которого ссылаются в своих публикациях на работы друг друга), а достигнутые данной научной группой результаты по тем или иным причинам не являются востребованными за ее пределами [2].

\section{Заключение}

Карты науки и патентные ландшафты являются компактными, информативными и наглядными формами визуализации наукометрической и библиометрической информации, отображающими взаимосвязи между различными аспектами научной и технической деятельности. При выполнении следующих условий:

1. использовании в качестве источников данных достаточно больших, надежных и представительных массивов информации;

2. применении современных методов обработки больших наборов данных;

3. применении комбинации взаимодополняющих подходов к анализу визуальных образов,

результаты исследования карт науки и патентных ландшафтов могут быть эффективно использованы при определении направлений и темпов научнотехнологического развития.

\section{Библиографический список}

1. Cobo M.J., Lopez-Herrera A.G., Herrera-Viedma E., Herrera F. Science mapping software tools: review, analysis, and cooperative study among tools // Journal of the American Society for Information Science and Technology. 2011. V. 62. № 7. P. 1382-1402.

2. Акоев М.А., Маркусова В.А., Москалева О.В., Писляков В.В. Руководство по наукометрии: индикаторы развития науки и технологии. Екатеринбург: Изд-во Урал. ун-та, 2014. - 250 с.

3. Trippe A. Guidelines for preparing patent landscape reports. WIPO, 2015. URL: http://www.wipo.int/edocs/pubdocs/en/wipo_pub_946.pdf (дата обращения: 11.04.2018). 
4. Маршакова-Шайкевич И.В. Роль библиометрии в оценке исследовательской активности науки // Управление большими системами. 2013. Выпуск 44. С. 210-247.

5. Бредихин С.В., Кузнецов А.Ю., Щербакова Н.Г. Анализ цитирования в библиометрии. Новосибирск: ИВМиМГ СО РАН, НЭИКОН, 2013. - 344 с.

6. Методические рекомендации по подготовке отчетов о патентном обзоре (патентный ландшафт). Приложение к Приказу Роспатента от 23.01.2017 № 8 «Об утверждении Методических рекомендаций по подготовке отчетов о патентном обзоре (патентный ландшафт)».

7. SciTech Strategies. URL: http://www.mapofscience.com (дата обращения: 09.11.2017).

8. 3D printing: a patent overview. Intellectual Property Office, 2013. URL: https://www.gov.uk/government/uploads/system/uploads/attachment_data/file/44523 2/3D_Printing_Report.pdf (дата обращения: 11.04.2018).

9. Кортов С.В., Шульгин Д.Б., Толмачев Д.Е., Егармина А.Д. Анализ технологических трендов на основе построения патентных ландшафтов // Экономика региона. 2017. Т. 13. Выпуск 3. С. 935-947.

10. Мазов Н.А. Свободно распространяемые программы для наукометрических и библиометрических исследований // Библиотеки и информационные ресурсы в современном мире науки, культуры, образования и бизнеса: 19-я междунар. конф. "Крым 2012" (2-10 июня 2012 г., г. Судак): Труды конф. М.: Изд-во ГПНТБ России, 2012. С. 1-6.

11. Мазов Н.А., Гуреев В.Н. Сравнительный анализ программного обеспечения для библиометрических исследований и построения карт науки // Библиотеки и информационные ресурсы в современном мире науки, культуры, образования и бизнеса: 20-я юбилейная Междунар. конф. "Крым 2013" (8-16 июня 2013 г., г. Судак): Труды конф. М.: Изд-во ГПНТБ России, 2013. С. 1-5.

12. Мазов Н.А., Гуреев В.Н. Программы для наукометрических и библиометрических исследований: краткий обзор и сравнительный анализ // Электронные библиотеки: перспективные методы и технологии, электронные коллекции: XV Всероссийская научная конференция RCDL' 2013, Ярославль, 14-17 октября 2013 г.: труды конференции. Ярославль: ЯрГУ, 2013. С. 122-127.

13. IN-SPIRE Visual Document Analysis. URL: http://in-spire.pnnl.gov (дата обращения: 11.04.2018).

14. VantagePoint. URL: https://www.thevantagepoint.com (дата обращения: 11.04.2018).

15. Derwent Innovation. URL: https://clarivate.com/products/derwentinnovation/ (дата обращения: 11.04.2018).

16. Orbit Intellixir. URL: http://www.intellixir.com (дата обращения: 11.04.2018).

17. CiteSpace. URL: http://cluster.cis.drexel.edu/ cchen/citespace (дата обращения: 11.04.2018). 
18. Science of Science Tool. URL: https://sci2.cns.iu.edu (дата обращения: 11.04.2018).

19. SciMAT. URL: http://sci2s.ugr.es/scimat/description.html (дата обращения: 11.04.2018).

20. Loet Leydesdorff's software. URL: http://www.leydesdorff.net/index.htm (дата обращения: 11.04.2018).

21. VOSviewer. URL: http://www.vosviewer.com (дата обращения: 11.04.2018).

22. Interdisciplinary Research. URL: http://www.idr.gatech.edu (дата обращения: 11.04.2018).

23. Network Workbench Tool. URL: http://nwb.cns.iu.edu (дата обращения: 11.04.2018).

24. CopalRed. URL: http://ec3.ugr.es/copalred (дата обращения: 11.04.2018).

25. Bibexcel. URL: http://www.soc.umu.se/english/research/bibexcel (дата обращения: 11.04.2018).

26. Scopus. URL: www.scopus.com (дата обращения: 11.04.2018).

27. Web of Science. URL: www.webofknowledge.com (дата обращения: 11.04.2018).

28. Академия Google. URL: https://scholar.google.ru/ (дата обращения: 11.04.2018).

29. Google Scholar - Search Tips. Content Coverage. URL: https://scholar.google.com/intl/us/scholar/help.html\#coverage (дата обращения: 11.04.2018).

30. Fagan J.C. An evidence-based review of academic web search engines, 2014-2016: implications for librarians' practice and research agenda // Information Technology and Libraries. 2017. V. 36. № 2. P. 7-47.

31. IEEE Xplore Digital Library. URL: http://ieeexplore.ieee.org (дата обращения: 11.04.2018).

32. PubMed. URL: www.ncbi.nlm.nih.gov/pubmed/ (дата обращения: 11.04.2018).

33. MathSciNet. URL: https://mathscinet.ams.org/mathscinet/index.html (дата обращения: 11.04.2018).

34. Научная электронная библиотека eLIBRARY.RU. URL: https://elibrary.ru (дата обращения: 11.04.2018).

35. Электронная библиотека диссертаций Российской государственной библиотеки. URL: http://diss.rsl.ru (дата обращения: 11.04.2018).

36. PATENTSCOPE. URL: https://patentscope.wipo.int/search/ru/search.jsf (дата обращения: 11.04.2018).

37. Espacenet. URL: https://worldwide.espacenet.com (дата обращения: 11.04.2018).

38. Информационно-поисковая система Федерального института промышленной собственности. URL: http://www1.fips.ru/wps/portal/IPS_Ru (дата обращения: 11.04.2018). 
39. Информационно-поисковая система Ведомства по патентам и торговым знакам США. URL: http://tmsearch.uspto.gov (дата обращения: 11.04.2018).

40. LexisNexis TotalPatent. URL: https://www.lexisnexis.com/totalpatent (дата обращения: 11.04.2018).

41. Global Patent Index. URL: http://www.epo.org/searching-forpatents/technical/espacenet/gpi.html (дата обращения: 11.04.2018).

42. PATSTAT. URL: https://www.epo.org/searching-forpatents/business/patstat.html (дата обращения: 11.04.2018).

43. Questel Orbit. URL: https://www.questel.com/software/ipbi/orbitintelligence (дата обращения: 11.04.2018).

44. Minesoft PatBase. URL: https://minesoft.com/our-products/patbase (дата обращения: 11.04.2018).

45. WIPS Global. URL: www.wipsglobal.com (дата обращения: 11.04.2018).

46. Gridlogics PatSeer. URL: https://patseer.com (дата обращения: 11.04.2018).

47. Kessler M.M. Bibliographic coupling between scientific papers // American Documentation. 1963. V. 14. № 1. P. 10-25.

48. Zhao D., Strotmann A. Evolution of research activities and intellectual influences in information science 1996-2005: introducing author bibliographiccoupling analysis // Journal of the American Society for Information Science and Technology. 2008. V. 59. № 13. P. 2070-2086.

49. Small H. Co-citation in the scientific literature: a new measure of the relationship between two documents // Journal of the American Society for Information Science. 1973. V. 24. № 4. P. 265-269.

50. White H.D., Griffith B.C. Author cocitation: a literature measure of intellectual structure // Journal of the American Society for Information Science. 1981. V. 32. № 3. P. 163-171.

51. He Q. Knowledge discovery through co-word analysis // Library Trends. 1999. V. 48. № 1. P. 133-159.

52. Coulter N., Monarch I., Konda S. Software engineering as seen through its research literature: a study in co-word analysis // Journal of the American Society for Information Science. 1998. V. 49. № 13. P. 1206-1223.

53. Borner K., Chen C., Boyack K. Visualizing knowledge domains // Annual Review of Information Science and Technology. 2003. V. 37. P. 179-255.

54. Cobo M.J., Lopez-Herrera A.G., Herrera-Viedma E., Herrera F. An approach for detecting, quantifying, and visualizing the evolution of a research field: a practical application to the fuzzy sets theory field // Journal of Informetrics. 2011. V. 5. № 1. P. 146-166.

55. Van Eck N.J., Waltman L. Software survey: VOSviewer, a computer program for bibliometric mapping // Scientometrics. 2010. V. 84. № 2. P. 523-538.

56. Interdisciplinary Research - Global Map 2006 (Science only). URL: http://www.idr.gatech.edu/detail.php?tab=1\&id=2 (дата обращения: 09.11.2017). 
57. Leydesdorff L., Rafols I. A global map of science based on the ISI subject categories // Journal of the American Society for Information Science and Technology. 2009. V. 60. № 2. P. 348-362.

58. Rafols I., Meyer M. Diversity and network coherence as indicators of interdisciplinarity: case studies in bionanoscience // Scientometrics. 2010. V. 82. № 2. P. 263-287.

59. Стрелецкий А., Забавников В., Асланов Э., Котлов Д. Патентный ландшафт сферы нанотехнологий // Форсайт. 2015. Т. 9. № 3. С. 40-53.

60. Chen C. CiteSpace II: detecting and visualizing emerging trends and transient patterns in scientific literature // Journal of the American Society for Information Science and Technology. 2006. V. 57. № 3. P. 359-377.

\section{Оглавление}

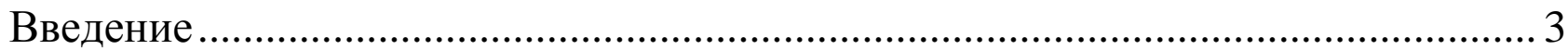

Карты науки и технологии: определение и области применения ……................... 3

Общая схема построения и анализа карт науки и технологии ................................ 7

Получение разнородных данных из различных информационных источников .. 7

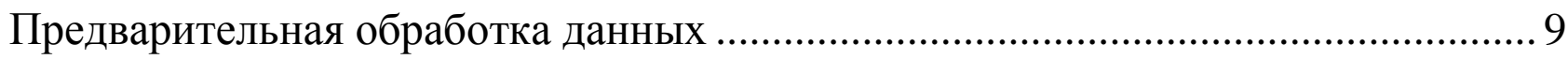

Формирование сетей (матриц, таблиц) взаимосвязей между данными ............... 10

Нормализация сетей (матриц, таблиц) ………................................................... 12

Построение карт науки и технологии …………................................................... 14

Визуализация карт науки и технологии ................................................................. 14

Анализ карт науки и технологии, получение предварительных выводов

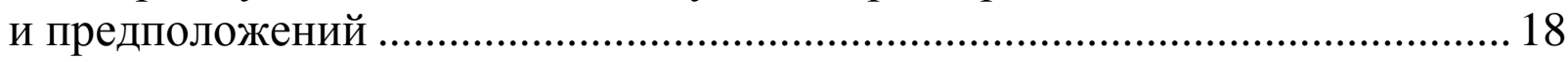

Экспертная оценка полученных выводов и предположений................................ 19

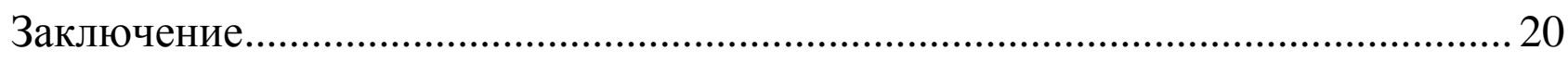

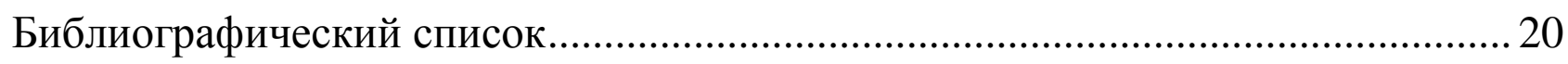

